\title{
Methane emissions in triple rice cropping: patterns and a
}

\section{method for reduction [version 1; peer review: 1 approved with}

\section{reservations, 1 not approved]}

\author{
Masato Oda (ii) 1, Huu Chiem Nguyen² \\ 1Japan International Research Center for Agricultural Sciences, Tsukuba, Japan \\ ${ }^{2}$ Department of Environmental Science, Can Tho University, Can Tho, Vietnam
}

V1 First published: 23 Sep 2019, 8:1675

https://doi.org/10.12688/f1000research.20046.1

Second version: 12 Nov 2019, 8:1675

https://doi.org/10.12688/f1000research.20046.2

Third version: 26 Feb 2020, 8:1675

https://doi.org/10.12688/f1000research.20046.3

Fourth version: 12 Mar 2020, 8:1675

https://doi.org/10.12688/f1000research.20046.4

Fifth version: 26 Jun 2020, 8:1675

https://doi.org/10.12688/f1000research.20046.5

Latest published: 15 Feb 2021, 8:1675

https://doi.org/10.12688/f1000research.20046.6

\section{Abstract}

The Mekong Delta paddies are known as hotspots of methane emission, but these emissions are not well studied. We analyzed methane emission patterns based on monitoring data from typical triple rice cropping paddies collected over 5 years. We found that the total emissions in a crop season doubled in the second crop, tripled in the third crop, and reset after the annual natural flood of the Mekong River. The emission peaks occurred around 0 to 3 weeks after starting irrigation, then gradually decreased. This suggests that methane was generated by the soil organic matter, because the small rice plants provide little carbon for methanogenesis. In general, the main source of emitted methane is rice-derived carbon by current-season photosynthates and the emission peaks at the rice heading stage. However, the contribution of the rice-derived carbon is negligible in the hotspot paddies while total emission is high. The increase in emission levels from the first to the third crop can be explained by the accumulation of rice residue from the preceding crops, especially rice straw incorporated into the soil. The reset of emission levels after annual flood means that the rice straw is decomposed without methanogenesis in water with dissolved oxygen. Thus, the annual emission pattern shows that decomposing rice straw in paddy surface-water is an effective method to reduce methane emissions.

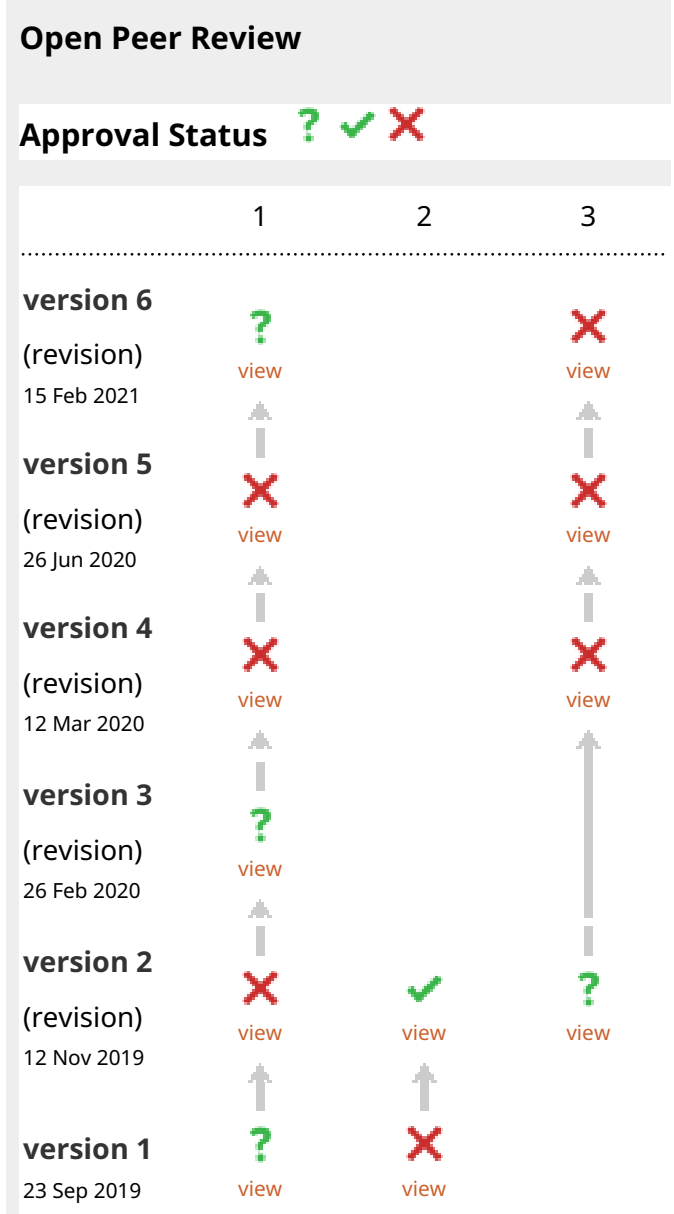

1. Arika Bridhikitti ID), Mahidol University Kanchanaburi Campus, Kanchanaburi, Thailand

2. Tran Dang Hoa, Huế University, Hue, 
Keywords

Greenhouse gases, Mekong Delta, Methanogenesis inhibition, Rice straw, Flooding, Methane reduction

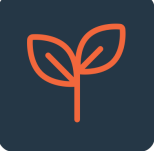

This article is included in the Agriculture, Food and Nutrition gateway.

\section{Vietnam}

3. Kazuyuki Yagi, King Mongkut's University of

Technology Thonburi, Bangkok, Thailand

Any reports and responses or comments on the article can be found at the end of the article.

\section{Corresponding author: Masato Oda (oda.masato@affrc.go.jp)}

Author roles: Oda M: Conceptualization, Data Curation, Formal Analysis, Methodology, Writing - Original Draft Preparation; Nguyen HC : Project Administration, Resources, Supervision

Competing interests: No competing interests were disclosed.

Grant information: The author(s) declared that no grants were involved in supporting this work.

Copyright: @ 2019 Oda M and Nguyen HC. This is an open access article distributed under the terms of the Creative Commons Attribution License, which permits unrestricted use, distribution, and reproduction in any medium, provided the original work is properly cited.

How to cite this article: Oda $\mathrm{M}$ and Nguyen HC. Methane emissions in triple rice cropping: patterns and a method for reduction [version 1; peer review: 1 approved with reservations, 1 not approved] F1000Research 2019, 8:1675

https://doi.org/10.12688/f1000research.20046.1

First published: 23 Sep 2019, 8:1675 https://doi.org/10.12688/f1000research.20046.1 


\section{Introduction}

The Mekong Delta produces 23.8 million tons of rice (General Statistics Office of Vietnam 2016). The climate of tropical monsoon (Am) enables high productivity by triple rice cropping (cropping three times a year). Rice paddies are a methane emission source, and the Mekong Delta is a hotspot (Arai et al., 2018; Werner et al., 2016). However, this has not been well studied (Vo et al., 2018).

The Mekong's natural flood of two months (starting from around late September to late October) limits the rice cultivation period. The $1^{\text {st }}$ crop (winter-spring) begins after the natural flood, then after harvesting the rice straw is incorporated into the soil. The $2^{\text {nd }}$ (spring-summer) and the $3^{\text {rd }}$ crop (summer-autumn) follows without interval. Just after the $3^{\text {rd }}$ crop, the natural flood starts so the straw is left on the paddies and decomposes under the floodwater. Then, the $1^{\text {st }}$ crop begins again without incorporation of the straw in the soil (field leveling only), because they are sufficiently decomposed by that time.

Can Tho University (CTU) and the Japan International Research Center for Agricultural Sciences (JIRCAS) conducted joint research and monitored methane emissions in typical triple rice cropping paddies for 5 years (for a total of 15 crops). The present study is a specific analysis of a part of the data set from this project. The results show that the strategy of decomposing rice straw on the surface water effectively reduces methane emission from the paddies.

\section{Methods}

\section{Site description}

The data were obtained from a farmer's paddies (three fields) in Thuan Hung village $\left(10^{\circ} 22^{\prime} \mathrm{N}, 105^{\circ} 58^{\prime} \mathrm{E}\right)$, Thot Not district, Can Tho city, Vietnam from 2011 to 2016. Normally, from May to October is the rainy season. The farmer managed the water with continuous flooding using a dike system. The rice variety Jasmine was used for the $1^{\text {st }}$ crop, and OM501 was used for the $2^{\text {nd }}$ and $3^{\text {rd }}$ crop every year. The average number of growth days per crop were 103,89 , and 92 , for the $1^{\text {st }}, 2^{\text {nd }}$, and $3^{\text {rd }}$ crops, respectively. The average intervals between the $1^{\text {st }}$ and the $2^{\text {nd }}$ crop and the $2^{\text {nd }}$ and the $3^{\text {rd }}$ crop were 5.16 and 6.6 days, respectively. This study was conducted with the approval of the farmer.

\section{Methane measurement}

We used the closed chamber method, described previously (Oda \& Chiem, 2019). In periods of natural flood, chambers with attached Styrofoam floats were used. Measurements were taken once a week throughout the rice growing stage, but every 3 days for 2 weeks after seeding, heading stage, and around draining.

\section{Statistical analysis}

Descriptive statistics were calculated using Microsoft Excel 2016.

\section{Results}

\section{Emission level}

According to the IPCC guidelines, standard methane emissions over 100 days of continuously flooding rice cropping are $130 \mathrm{~kg} \mathrm{ha}^{-1} \mathrm{crop}^{-1}$. Wassmann et al. (1996) reported very high emissions (160-240 $\mathrm{kg} \mathrm{ha}^{-1} \mathrm{crop}^{-1}$ ) from double cropping rice paddies in the Philippines after organic matter incorporation. However, we observed larger emissions (710-1845 $\mathrm{kg} \mathrm{ha}^{-1} \mathrm{crop}^{-1}$ ). The emission level doubled in the $2^{\text {nd }}$ crop, and tripled in the $3^{\text {rd }}$ crop, then reset after the natural flood (Figure 1). Furthermore, the total emissions during the flood period and the $1^{\text {st }}$ crop was lower than that of the $3^{\text {rd }}$ crop (Figure 1). The total emission should be higher than that of the $3^{\text {rd }}$ crop; because, the absence of rice plants doubles the methane emission from the field (Oda \& Chiem, 2019). Note, we confirmed that no rice straw (the source of methanogenesis) was lost to the floodwater. Raw results are available as Underlying data (Oda, 2019a).

\section{Emission pattern}

The previous study (Oda \& Chiem, 2019) indicated three types of methane emission patterns during the rice growth period. Generally, the emissions peak at the heading stage due to the methanogenesis substrate provided by the present rice. Another pattern can occur with an additional peak at the early stage of rice growth if organic matter was incorporated beforehand. The third is the pattern in the triple rice cropping. The emission peaks at the early stage of rice growth, then gradually decreases; the peak at the heading stage is undetectable because of the high emission levels. This means the contribution of the rice-derived carbon is small. In the present study, the pattern was the same as the previous study (Oda \& Chiem, 2019). The emissions began with irrigation, reached peaks from 0 to 3 weeks after the start of irrigation (see Extended data, Supplemental figure; Oda, 2019b), and gradually decreased, and the peak at the heading stage was undetected. Furthermore, the emissions during the natural flood appeared to be a continuation of the emissions of the $3^{\text {rd }}$ crop (Figure 2).

\section{Discussion}

\section{Emission pattern}

The total emissions in a crop season doubled in the second crop, tripled in the third crop, and reset after the natural flood. This can be explained by the accumulation of rice residue from the

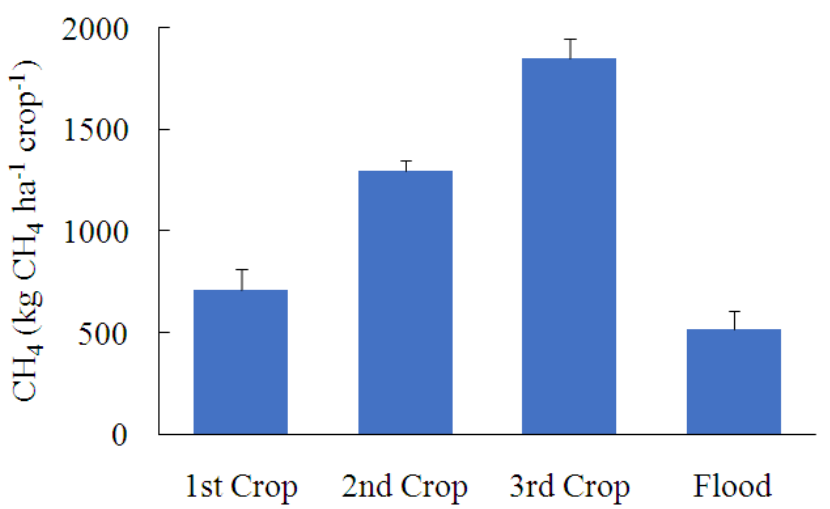

Figure 1. Total $\mathrm{CH}_{4}$ emissions. Five-year average of $\mathrm{CH}_{4}$ emissions of triple-cropped rice paddies in the Mekong Delta (2011-2016). Error bars are standard deviation $(n=15)$. 


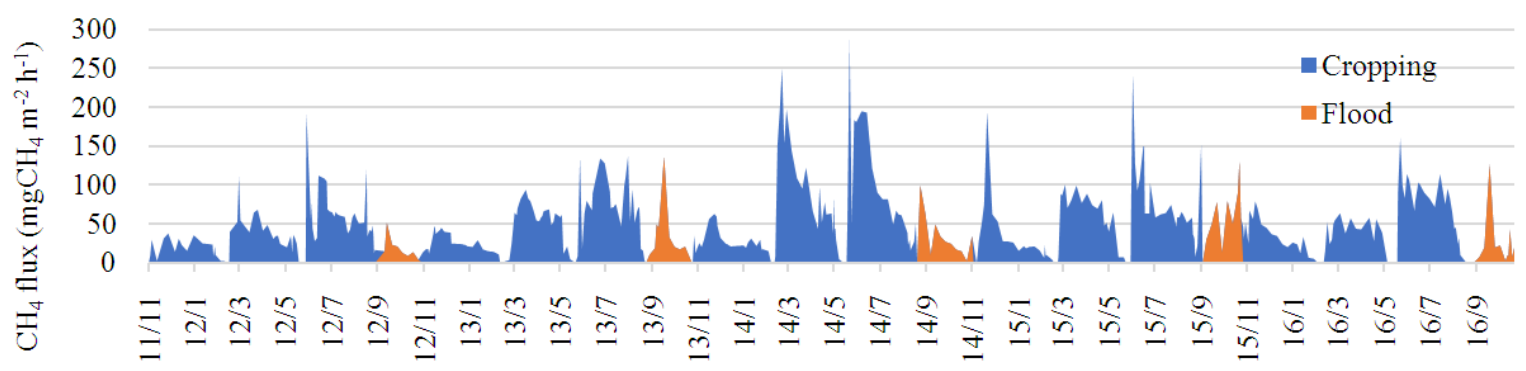

Date (yy/m)

Figure 2. Actual $\mathbf{C H}_{4}$ emissions. $\mathrm{CH}_{4}$ emissions of triple crop rice paddies in the Mekong Delta (2011-2016). Data are the mean of three replications.

preceding crops, especially by the rice straw incorporated into the soil, because the contribution of the present rice-derived carbon is small.

The reset of emission levels after the annual flood means that the rice straw is decomposed without methanogenesis in water because the water includes dissolved oxygen. The fact that the emissions under natural flood appeared to be a continuation of the emissions of the 3 rd crop suggests that the rice straw on the paddy surface contribute to no methane emission. A portion of emission in the first crop will be caused by incorporation of the remaining rice straw related to the leveling of the field.

Method for methane reduction

Our results indicate that the main cause of the increase in methane emissions was the incorporation of rice straw into the soil. In contrast, decomposing rice straw in paddy surface-water generated less methane. Thus, decomposing rice straw in paddy surface-water is an effective method to reduce methane emissions.

\section{Conclusion}

We analyzed the methane emission patterns of triple rice cropping paddies in the Mekong Delta. Methane emissions increased with rice straw incorporation into the soil. The natural flood resulted in decomposition occurring in the water, leading to less methane emission. Therefore, the annual emission pattern suggests that decomposing rice straw in paddy surfacewater is an effective method to reduce methane emissions. The development of practical technology to attain this reduction is a subject for a future study.

\section{Data availability}

Underlying data

Figshare: Methane emission from triple cropping rice field. https://doi.org/10.6084/m9.figshare.9757934.v1 (Oda, 2019a).

\section{Extended data}

Figshare: Methane flux of days after transplanting. https://doi. org/10.6084/m9.figshare.9746006.v1 (Oda, 2019b).

Data are available under the terms of the Creative Commons Attribution 4.0 International license (CC-BY 4.0)

\section{Acknowledgements}

We thank our former colleagues for the use of legacy data.
Anon: Impact of climate change on future rice production in the Mekong River Delta. CCAFS: CGIAR research program on Climate Change, Agriculture and Food Security [Online]. [Accessed: 30 August 2019].

Reference Source

Arai $\mathrm{H}$, Takeuchi W, Oyoshi K, et al:: Estimation of Methane Emissions from Rice Paddies in the Mekong Delta Based on Land Surface Dynamics Characterization with Remote Sensing. Remote Sens. 2018; 10(9): 1438. Publisher Full Text

Oda M: Methane emission from triple cropping rice field. figshare. Dataset. 2019 a.

http://www.doi.org/10.6084/m9.figshare.9757934.v1

Oda M: Methane flux of days after transplanting. figshare. Figure. 2019b. http://www.doi.org/10.6084/m9.figshare.9746006.v1

Oda M, Chiem NH: Rice plants reduce methane emissions in high-emitting paddies [version 3; peer review: 2 approved, 1 approved with reservations]
F1000Res. 2019; 7: 1349

PubMed Abstract | Publisher Full Text | Free Full Text

Vo TBT, Wassmann $\mathrm{R}$, Tirol-Padre A, et al: Methane emission from rice cultivation in different agro-ecological zones of the Mekong river delta: seasonal patterns and emission factors for baseline water management. SSPN. 2018; 64(1): 47-58.

Publisher Full Text

Wassmann R, Neue $\mathrm{HU}$, Alberto MC, et al: Fluxes and pools of methane in wetland rice soils with varying organic inputs. Environ Monit Assess. 1996; 42(1-2): 163-173.

PubMed Abstract | Publisher Full Text

Werner $\mathrm{C}$, Kraus D, Mai TV et al: $\mathrm{CH}_{\text {and }} \mathrm{N}_{2} \mathrm{O}$ Emissions from Rice Paddy Soils in Vietnam - Identifying Regional Hotspots and Quantifying the Total Emission Strength Using a Biogeochemical Model. AGU Fall Meeting Abstracts. 2016. Reference Source 


\section{Open Peer Review}

\section{Current Peer Review Status: ? $\mathrm{X}$}

\section{Version 1}

Reviewer Report 23 October 2019

https://doi.org/10.5256/f1000research.22010.r54181

(C) 2019 Dang Hoa T. This is an open access peer review report distributed under the terms of the Creative Commons Attribution License, which permits unrestricted use, distribution, and reproduction in any medium, provided the original work is properly cited.

\section{Tran Dang Hoa}

University of Agriculture and Forestry, Huế University, Hue, Vietnam

The measurement of GHG emission from paddy fields in Mekong Delta have been carried out by several authors. However, understanding of GHG emission from paddy field by triple seasons isn't well known. This study contributed some good information on GHG emission, focusing on $\mathrm{CH}_{4}$ to understanding how to reduce GHG emission from the paddy field.

My commends are below:

\section{Introduction:}

Method:

Introduction should be given a general information on rice production in Mekong Delta in order to explain this study is a representative.

Site description should be more clear, such as, what about the field practices of the farmer on their fields? Were the three observed fields similar in these practices? What about the water management in the fields? The author said the fields was continuously flooding, but how about water level/regime in three observed fields? How about straw management? What about the height of stubble for each season? How was about fertilization?...

Methane measurement: The author said the closed chamber method described by Oda \&Chien, 2019. However, a brief description should be added. What time of the day were GAS samples take? How was $\mathrm{CH}_{4}$ calculated?

Statistical analysis: A one-way ANOVA should be analysed to compare the means among season?

\section{Discussion:}

The authors just explained the difference of $\mathrm{CH}_{4}$ emission among seasons was due to straw incorporation into the soil. However, I did not see any information on straw incorporation in the observed fields (as above commented). Other factors such as rice varieties, weather, 
fertilization... should be discussed. In this case, these factors differed among seasons, why did only straw incorporation influence on $\mathrm{CH}_{4}$ emissions?

\section{Conclusion:}

As above commented, the conclusion on $\mathrm{CH}^{4}$ emission increase being due to straw incorporation is not clear.

Is the work clearly and accurately presented and does it cite the current literature? Yes

Is the study design appropriate and is the work technically sound?

Yes

Are sufficient details of methods and analysis provided to allow replication by others? Partly

If applicable, is the statistical analysis and its interpretation appropriate?

Partly

Are all the source data underlying the results available to ensure full reproducibility? Yes

Are the conclusions drawn adequately supported by the results? Partly

Competing Interests: No competing interests were disclosed.

Reviewer Expertise: Low carbon rice production

I confirm that I have read this submission and believe that I have an appropriate level of expertise to state that I do not consider it to be of an acceptable scientific standard, for reasons outlined above.

Author Response 05 Nov 2019

Masato Oda, Japan International Research Center for Agricultural Sciences, Tsukuba, Japan

Thank you very much for giving valuable comments.

1. Introduction: a general information in order to explain this study is a representative Thank you. We added.

2. Methods

2-1. Site description:

The sentence was improved to clarify that the present study was an observation of typical farmer's paddies mentioned in the introduction (including rice straw treatment). 


\section{2-2. Farmers practices:}

Thank you. We added the reference. The height of the stubble is about $30 \mathrm{~cm}$. The daily average water levels were monitored with water level loggers at the corner of the fields; the average levels were $2.0 \mathrm{~cm}(-0.6$ to $6.1 \mathrm{~cm})$ until drained (the data will be published in another paper).

\section{2-3. Methane measurement:}

Thank you. We added.

\section{Statistical analysis:}

Figure 1 is clear enough to omit ANOVA (see the standard deviation (not SE)).

\section{Discussion:}

The information on straw incorporation in the observed fields is mentioned in the introduction. Rice straw incorporation enhances methane emission. We added a referred to our previous study that is a kind of short review of the effect of straw incorporation.

Competing Interests: No competing interests were disclosed.

Reviewer Report 18 October 2019

https://doi.org/10.5256/f1000research.22010.r54183

(C) 2019 Bridhikitti A. This is an open access peer review report distributed under the terms of the Creative Commons Attribution License, which permits unrestricted use, distribution, and reproduction in any medium, provided the original work is properly cited.

\section{Arika Bridhikitti}

Environmental Engineering and Disaster Management Program, Mahidol University Kanchanaburi Campus, Kanchanaburi, Thailand

The idea of estimating methane emissions from rice paddy fields is not novel. Many publications, including those conducted in SE Asia, have been widely accepted, such that collected and reported in the 1996 IPCC Guidelines for National Greenhouse Gas Inventories: Reference Manual. The study on triple rice cropping in the Mekong River Delta is quite interesting since few studies carried on such the cropping system, but usually estimating the total flux based upon one single cropping experiment.

My first significant concern in this work is involved with the methodology of methane sampling and analysis. The closed chamber method used in this study (Oda and Chiem, 2019) had not yet been validated with other traditional closed chamber studies. Furthermore, methane emission using this method seems to return significantly higher methane emissions compared to those emissions reported worldwide in the IPCC report. Since very much high emission rates can result in 
significantly overestimating methane emissions from the SE Asia region, I suggest the authors carefully discuss the reliability of the proposed method in comparison to the traditional method.

My last concern is on the suggestions given by the authors. They claim that decomposing rice straw in paddy surface-water (nonrice period) is an effective method to reduce methane emissions. This

suggestion is not conforming to the fact that the wetland system is a significant source of methane

emission. I think the author could mean lower methane emission during the nonrice flooding period, but the conclusion written in the manuscript is not clear that way. Although, I think the conclusion given by the authors is not feasible since promoting long-term nonrice flooding instead of rice cropping could mean lower rice yield.

Is the work clearly and accurately presented and does it cite the current literature? Yes

Is the study design appropriate and is the work technically sound?

Yes

Are sufficient details of methods and analysis provided to allow replication by others? No

If applicable, is the statistical analysis and its interpretation appropriate? Not applicable

Are all the source data underlying the results available to ensure full reproducibility? No

Are the conclusions drawn adequately supported by the results? Partly

Competing Interests: No competing interests were disclosed.

I confirm that I have read this submission and believe that I have an appropriate level of expertise to confirm that it is of an acceptable scientific standard, however I have significant reservations, as outlined above.

Author Response 05 Nov 2019

Masato Oda, Japan International Research Center for Agricultural Sciences, Tsukuba, Japan

Thank you for giving valuable comments for improving our manuscript.

1. The methodology of methane sampling and analysis.

Our methodology is the traditional method and there are high emission data in An Giang province. The water management conditions are better than our site because of the fulldike system. Thus, we think our data are reliable. We added the explanations. 


\section{Suggestion by authors}

We agree with you that the wetland system is a significant source of methane emission. We also agree with you that the methane emission in the paddy field is extremely high compared to the simple wetland. Our finding is that the cause of the high emission in the paddy field is the incorporation of rice straws. The recent spread of combine harvesting decreases the need for rice straw burning. The methane emission will increase much more. Therefore, decreasing the methane emission of the paddy field to the levels of the simple wetland is still significant according to the data. Our suggestion is directly led by the results of the present study; although there are many other indirect options.

For the yield of rice, we think by the profit. A recent study reported that the profit of triple rice is only 6\% higher than double cropping (J Environ Manage. 2018). However, utilizing rice straw enables organic farming and that brings much profit by the high unit price. We are trying to establish cultivation practice. Furthermore, using the ratooning triple cropping is also possible.

Competing Interests: No competing interests were disclosed.

The benefits of publishing with F1000Research:

- Your article is published within days, with no editorial bias

- You can publish traditional articles, null/negative results, case reports, data notes and more

- The peer review process is transparent and collaborative

- Your article is indexed in PubMed after passing peer review

- Dedicated customer support at every stage

For pre-submission enquiries, contact research@f1000.com 